\title{
Implementation of a DSPACE-based standalone renewable energy supply feeding an isolated load
}

\author{
Mohamed Barara ${ }^{1}$ Chimezie Adiuku ${ }^{2}$ Abdul Rhaiman Beig ${ }^{2}$. \\ Khalifa Hasan Alhosani ${ }^{2} \cdot$ Naji Al Sayari ${ }^{2} \cdot$ Mohamed Akherraz $^{1}$
}

Received: 18 September 2015/ Accepted: 1 March 2016/Published online: 17 March 2016

(c) The Author(s) 2016. This article is published with open access at Springerlink.com

\begin{abstract}
This paper deals with standalone small power generation employing three self-excited induction generators under varying speeds feeding an isolated load. The proposed system utilizes three-level cascaded H-bridge inverter for the three generators. The control scheme has the capability of regulating the output voltage for balanced operation of a three-phase isolated load under variable speed. The proposed control can be implemented using DSPACE 1104, and the experimental results are presented to demonstrate the effectiveness of the proposed controller for an isolated generating system.
\end{abstract}

Keywords Renewable energy - Multilevel inverter .

Voltage control

\section{List of symbols}

$\begin{array}{ll}R_{\mathrm{S}} & \text { Stator resistance } \\ R_{\mathrm{r}} & \text { Rotor resistance } \\ l_{\mathrm{S}} & \text { Stator leakage inductance } \\ l_{\mathrm{r}} & \text { Rotor leakage inductance } \\ L_{\mathrm{m}} & \text { Mutual inductance } \\ V_{\mathrm{cd}}, V_{\mathrm{cq}} & \text { Direct and quadrature axes stator } \\ i_{\mathrm{ds}}, i_{\mathrm{qs}} i_{\mathrm{dr}}, i_{\mathrm{qr}} & \text { Direct and quadrature axes stator and rotor } \\ & \text { current, respectively } \\ c & \text { AC capacitance } \\ P & \text { Number of poles }\end{array}$

Mohamed Barara

mohamed-barara@hotmail.fr

1 Department of Electrical Engineering, Mohamed V University, EMI, Rabat, Morocco

2 Department of Electrical Engineering, The Petroleum Institute, Abu Dhabi, United Arab Emirates
$K_{d}$ and $K_{q}$

Constants which represent the initially induced voltages along the $d$-axis and $q$-axis $M \quad$ Modulation index

$V_{\mathrm{r}}$

$V_{\mathrm{c}}$

$V_{\mathrm{s}}$

$\sigma$

$p$

$V_{\text {rms }}$

$I_{\mathrm{m}}$

SPWM

Amplitude of the reference signal

Amplitude of the control signal

Input voltage

Width of the $m$ th pulse

Number of pulses per half-cycle

RMS voltage

Magnetizing current

Sinusoidal pulse width modulation

\section{Introduction}

Recently, a lot of research has taken place in the design and control of renewable energy systems such as solar, wind, hydraulic and biomass, because they are sustainable, costeffective and alternatives for conventional energy sources.

For isolated and remote areas, it may not be practical or economically viable to provide a connection to the distribution grid system, where utility lines are uneconomical to install due to the terrain and geographical condition difficulties.

In the literature, regarding the efficient integration of renewable sources for supplying remote power systems, Sonia Leva $[1,2]$ presents a techno-economic analysis about the possible implementation of hybrid systems (photovoltaic and wind energy) on an existing plant for supplying isolated applications such as industrial applications related to telecommunications. In terms of the stability of an isolated system, the author [3] presents a theoretical approach for the dynamic stability analysis in case power-quality disturbances such as unbalances, harmonics, and inter harmonics take place. The pollution, 
resulting from the current and voltage the system acquires, may cause stability problems especially in isolated electric plants where small generators, supply motor drives, static converters, or nonlinear loads are involved. The present study constitutes a technical investigation, aiming at hardware implementation, to control small power generators, based on self-excited induction generators, and provides a versatile way to investigate different hybrid schemes of renewable energy generation fuel cell and PV.

Self-excited induction generators (SIEG) have been found to be very suitable for small power generation by small or micro-hydro as well as wind systems; they provide a promising solution for isolated areas to generate electrical energy because of the low price, mechanical simplicity and robust structure.

The use of cage induction machine connected to the fixed bank capacity has the advantage of simplicity in implementation and low cost due to the absence of a static converter. However, this configuration allows operating limits which must be taken into account, especially changes in amplitude and voltage frequency during load and speed variations [4]. In the literature, many authors [5-9] have discussed different criteria for selecting the limiting value of capacitance and speed for successful operation of SEIG under various conditions.

With regard to the drawback of this machine, the output voltage is affected by the load and speed condition. A number of schemes have been suggested for regulating the terminal voltage and have been reported in literature [1016]. Since there is limited work published on the application of multilevel for the control of several SEIGs working in parallel and independent. Also, the literature is very limited on the application of H-bridge inverters in standalone systems, where they have several advantages, namely low distortion voltages and currents and low switching losses and the power can be efficiently transferred from different generators with better power quality.

The aim of this paper is to examine this technology for small power generation using self-excited induction generators. It is hoped that this will draw the attention of researchers toward its application, especially for remote and isolated locations. An attempt is made to control the terminal voltage and frequency from the number of SIEGs connected to multilevel converters.

Multilevel converters have been under research and development for more than three decades and have found successful industrial application. In recent years, many publications have addressed multilevel converter technology and stressed the growing importance of multilevel converters for high-power applications [17]. The most popular multilevel converter topologies are flying capacitor (FC), cascaded H-bridge (CHB) converters and neutral point clamped (NPC).
The cascaded H-bridge multilevel topology is the most convenient model compared to other topologies according to the required switching devices. This topology requires separate DC sources for each H-bridge which is an advantage for applications such as renewable or alternative energy sources, because it offers a modular solution by collecting large numbers of PV panels or generator as isolated DC sources, which allows generating a large number of voltage levels in the output. However, this advantage comes along with drawbacks, which are the inherent power imbalance between generators in each leg as well as a power imbalance among the different phases of the inverter $[18,19]$; this condition will affect the performance of the CHB and load.

In this paper, the two types of imbalances will be addressed sequentially in the control strategy: first, the phase imbalanced is compensated through the modification of the phase references, and the amplitude imbalance is compensated by generating the same reference voltage, because the voltage generated by the SIEGs depends strongly on the variation of the prime mover.

A suitable topology has been proposed, through the design and control of an inverter for isolated load to efficiently make use of energy from the generators. The proposed inverter includes three H-bridges and four SPWM switching signals to control each bridge, respectively. The operating principle and design guidelines of the proposed scheme are presented along with the performance analysis and simulation using MATLAB Simulink with three selfexcited induction generators operating at different variable speeds.

The experimental prototype has been developed for the validation of the proposed converter system. The Dspace controller is used to transfer the PWM signals and to feed back the voltage signals of each phase load voltage. The error between the reference RMS phase voltage and the feedback RMS phase voltages are used to effectively generate proper PWM signals to drive IGBTs of the controlled power converter.

The rest of this paper is organized as follows. The system configuration for small power generation is presented in "Configuration of the proposed standalone system". The control scheme and hardware configuration are presented in "Configuration control algorithm". The last section shows the simulation, experiment results and discussion.

\section{Configuration of the proposed standalone system}

The system is designed for an isolated location. The complete configuration of the proposed generation system using an SEIG is shown in Fig. 1. The self-excited 


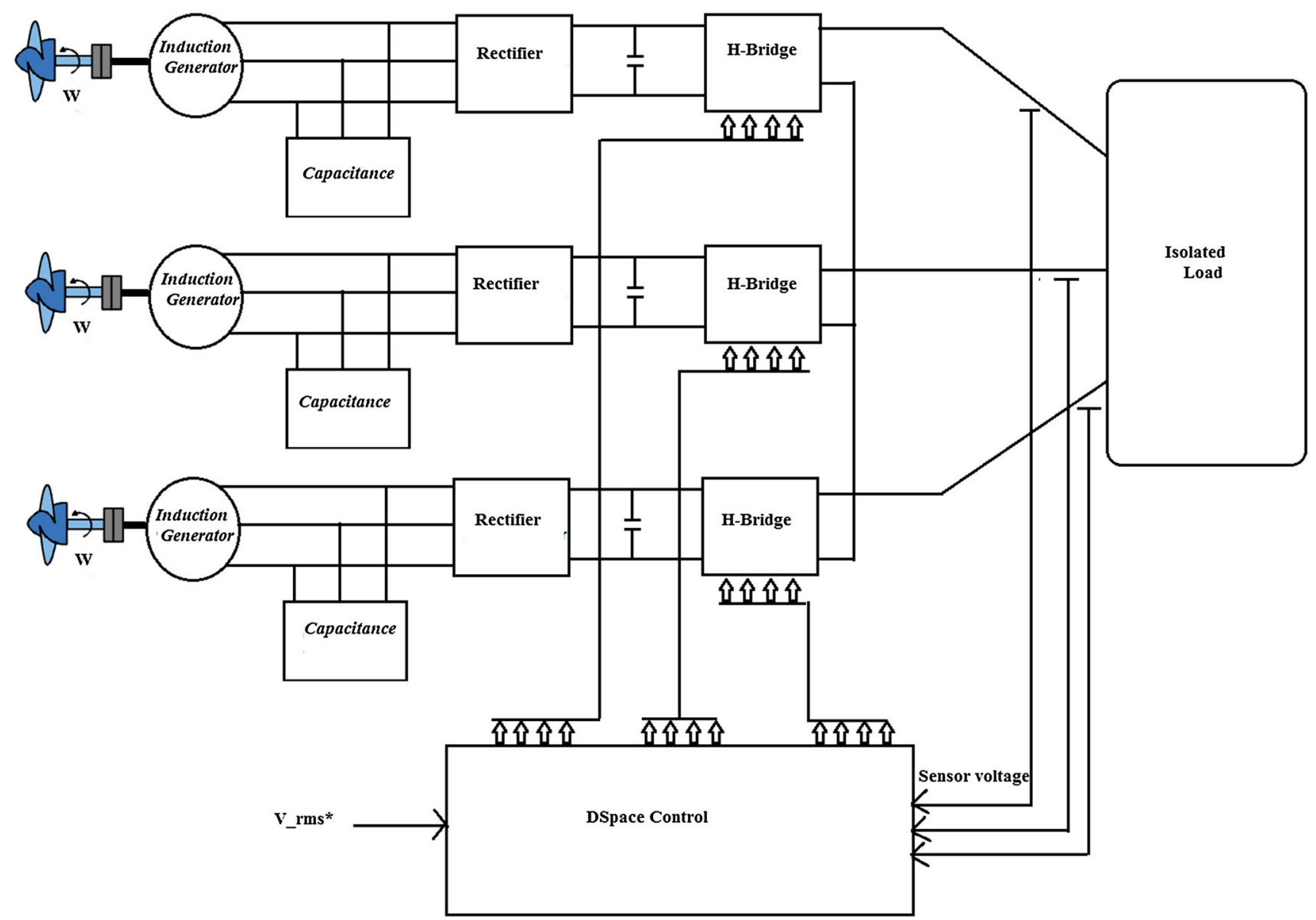

Fig. 1 Configuration of the proposed standalone system

induction generator using three-phase AC capacitors can start its voltage buildup from a remnant magnetic flux in the core. This voltage buildup starts when the induction generators are driven at a given speed and an appropriate capacitance is connected at its terminals. The DC sources of each single-phase H-Bridge inverter are obtained from three-phase diode rectifiers powered by self-excited induction generators.

The following sections present the modelling of all subsystems of the proposed system. The main components are SIEG, three-phase diode rectifier, three-level cascaded $\mathrm{H}$-bridge inverter and AC load.

\section{Self-excited induction generator}

Including initial conditions, i.e. initial voltage in the capacitors and remnant magnetic flux in the core, one can obtain the following differential equation. The state-space form of the induction generator in the q-d synchronously rotating reference frame is given by [20]:

$$
\begin{aligned}
& \frac{\mathrm{d}}{\mathrm{d} t}=A I+B \\
& I=\left[\begin{array}{c}
i_{\mathrm{qs}} \\
i_{\mathrm{ds}} \\
i_{\mathrm{qr}} \\
i_{\mathrm{dr}}
\end{array}\right], \quad B=\left[\begin{array}{cc}
L_{\mathrm{m}} K_{\mathrm{q}} & -L_{\mathrm{r}} V_{\mathrm{cq}} \\
L_{\mathrm{m}} K_{\mathrm{d}} & -L_{\mathrm{r}} V_{\mathrm{cd}} \\
L_{\mathrm{m}} V_{\mathrm{cq}} & -L_{\mathrm{s}} K_{\mathrm{q}} \\
L_{\mathrm{m}} V_{\mathrm{cd}} & -L_{\mathrm{s}} K_{\mathrm{d}}
\end{array}\right], \\
& A=\frac{1}{L}\left[\begin{array}{ccc}
-L_{\mathrm{r}} R_{\mathrm{s}} & -L_{\mathrm{m}}^{2} w_{\mathrm{r}} L_{\mathrm{m}} R_{\mathrm{r}} & -L_{\mathrm{m}} w_{\mathrm{r}} L_{\mathrm{r}} \\
L_{\mathrm{m}}^{2} w_{\mathrm{r}} & -L_{\mathrm{s}} R_{\mathrm{s}} L_{\mathrm{m}} w_{\mathrm{r}} & L_{\mathrm{r}} L_{\mathrm{m}} R_{\mathrm{r}} \\
L_{\mathrm{m}} R_{\mathrm{s}} L_{\mathrm{s}} w_{\mathrm{r}} L_{\mathrm{m}} & -L_{\mathrm{s}} R_{\mathrm{r}} & -L_{\mathrm{s}} w_{\mathrm{r}} L_{\mathrm{r}} \\
-L_{\mathrm{s}} w_{\mathrm{r}} L_{\mathrm{r}} L_{\mathrm{m}} R_{\mathrm{s}} & -L_{\mathrm{s}} w_{\mathrm{r}} L_{\mathrm{r}} & -L_{\mathrm{s}} R_{\mathrm{r}}
\end{array}\right]
\end{aligned}
$$

where $L=L_{\mathrm{r}} L_{\mathrm{s}}-L_{\mathrm{m}}^{2}$.

The excitation system model is:

$V_{\mathrm{cq}}=1 / c\left(i_{\mathrm{qs}}-i_{\mathrm{rlq}}\right) \mathrm{d} t$

$V_{\mathrm{cd}}=1 / c\left(i_{\mathrm{ds} \_} i_{\mathrm{rld}}\right) \mathrm{d} t$

where $i_{\mathrm{r}} d$ and $i_{\mathrm{r}} q$ are input currents of the three-phase diode bridge rectifier. 
The instantaneous amplitude of the magnetizing current of the SEIG is computed as:

$I_{m}=\sqrt{\left(i_{\mathrm{qs}}+i_{\mathrm{qr}}\right)^{2}+\left(i_{\mathrm{ds}}+i_{\mathrm{dr}}\right)^{2}}$.

\section{Three-phase diode rectifier}

Three-phase diode bridge rectifier is used to convert the variable magnitude, variable frequency voltage at the induction generator terminal into DC voltage. The circuit consists of six diodes, a top group of three diodes and a bottom group of three diodes.

\section{Three-level cascaded H-bridge inverter}

Cascaded H-bridge inverter is seen as the most suitable topology for the integration of the renewable energy, since the separate DC sources that it requires can be directly fed by PV arrays, wind turbine or fuel cells. The three-level cascaded H-bridge inverter consists of three identical single-phase $\mathrm{H}$-bridges in each phase (HB_A, HB_B and HB_C). Each HB is supplied by a separate DC source, where $\mathrm{V}$ is the unit voltage. Each $\mathrm{HB}$ generates three voltages at the output: $+\mathrm{V}, 0$ and $-\mathrm{V}$, Each H-bridge has three-switching states as defined in Table 1.

\section{Configuration control algorithm}

The control system permits the independent control for each H-bridge inverter; three PI controllers are necessary for independent control of each output of H-Bridge as shown in Fig. 2.

The H-bridge topology has a left leg and a right leg. The phase shift between the upper $\mathrm{H}$-bridge and the lower H-bridge is $90^{\circ}$ and between each H-bridge $120^{\circ}$. The reference of each output voltage is the same for the three H-bridges. A two sinusoidal reference signal is compared to a triangular waveform to generate switching

Table 1 Switching state definitions for phase $\mathrm{R}$

\begin{tabular}{lll}
\hline State & $v_{\mathrm{R} o}$ & Status of switches \\
\hline+1 & $+\mathrm{V}$ & $\mathrm{S} 1, \mathrm{~S} 2$ are on, and S3, S4 are off \\
0 & 0 & S1, S3 are on, and S2, S4 are off OR S2, S4 are on, and S1, S3 are off \\
-1 & $-\mathrm{V}$ & S3, S4 are on, and S1, S2 are off \\
\hline
\end{tabular}

Fig. 2 Control strategy of the proposed system

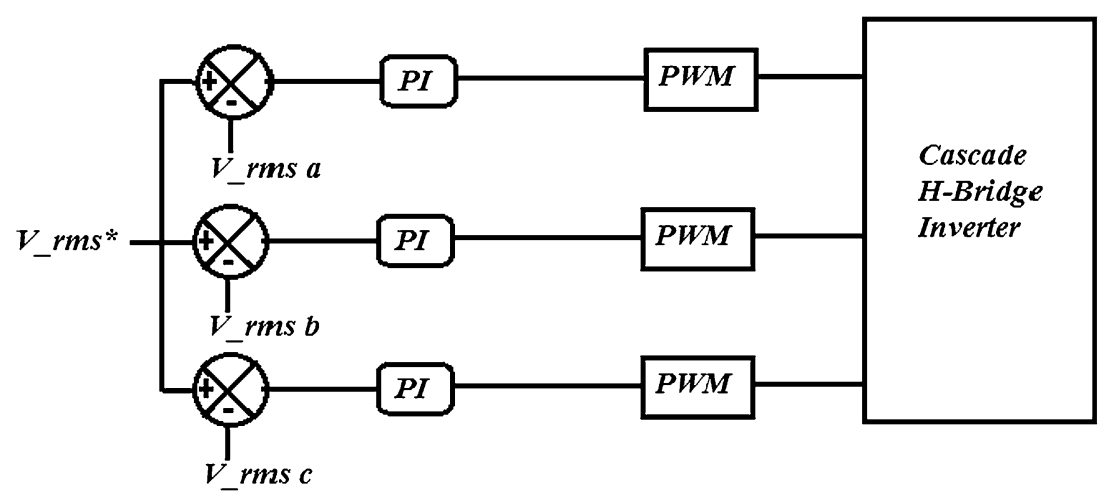

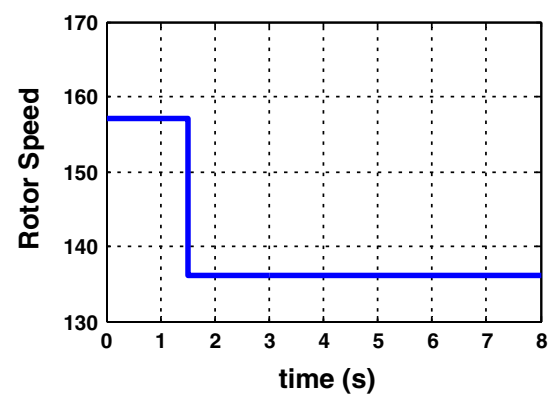

a

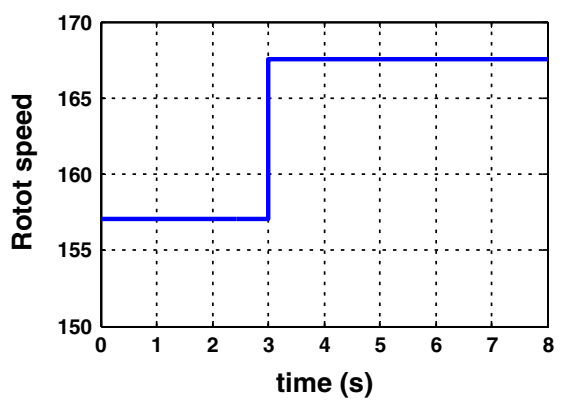

b

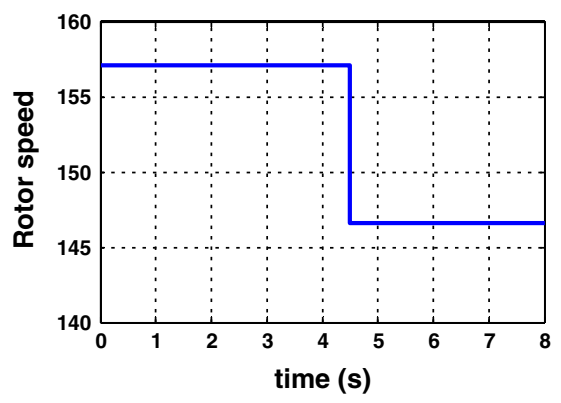

c

Fig. 3 Variation rotor speed of the three generators: a SIEG 1, b SIEG 2, c SIEG 3 
signals of inverter block in the SPWM modulation technique. The sinusoidal waveform is known as modulating signal and its frequency is $50 \mathrm{~Hz}$. The triangular waveform is generated at a high frequency as carrier of modulation. The RMS output voltage of the H-bridge can be varied by changing the modulation index, $M$. The conventional PI controller is employed to adjust the equivalent modulation index.

$M=\frac{V_{\mathrm{r}}}{V_{\mathrm{c}}}$,

where, $V_{\mathrm{r}}$ is the amplitude of the reference signal and $V_{\mathrm{c}}$ is the amplitude of the control signal.

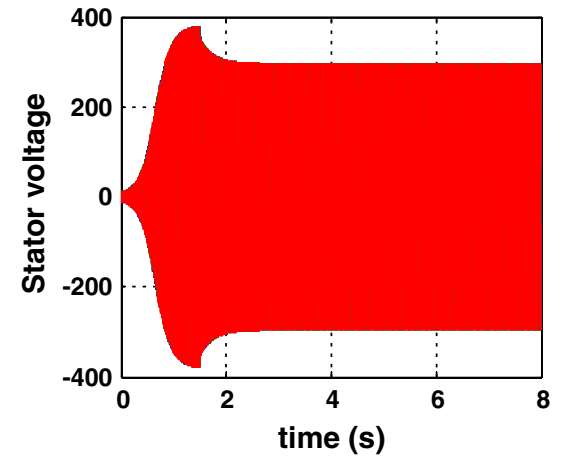

a

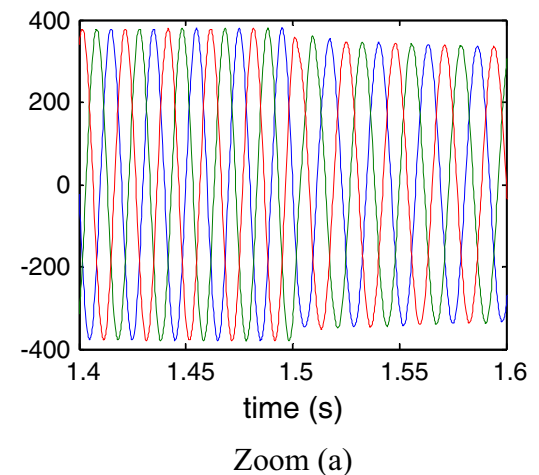

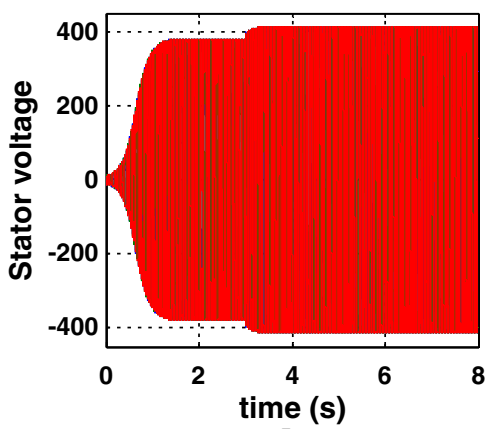

b

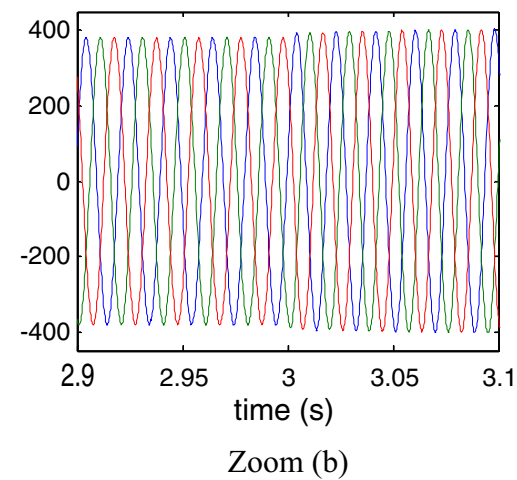

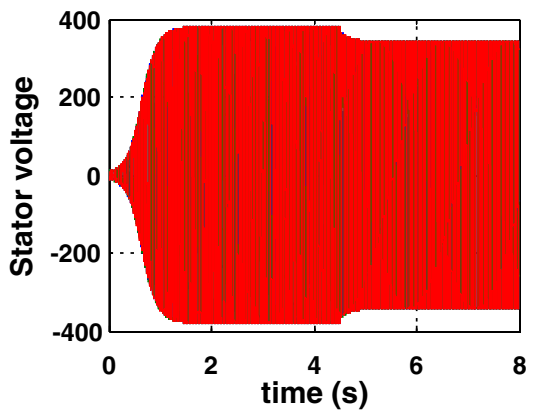

c

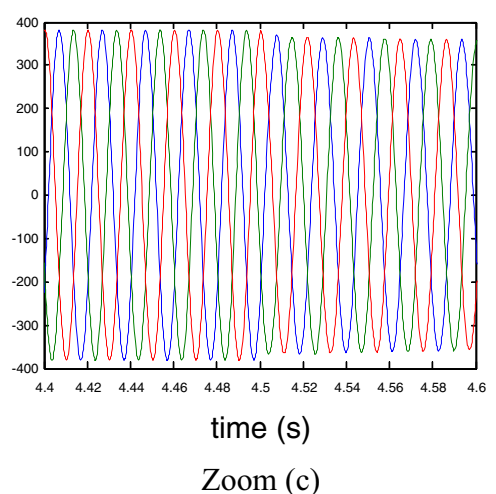

Fig. 4 Terminal stator voltage of the three generators: a SIEG 1, b SIEG 2, c SIEG 3

Fig. 5 DC link voltage of the three generators: blue (SIEG 1), red (SIEG 2), green (SIEG 3)

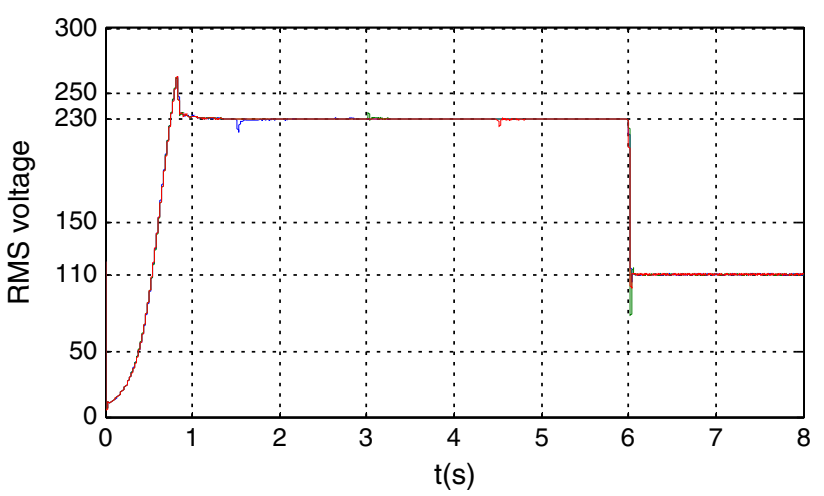

Fig. 6 RMS control voltages of the three-cascade H-bridge 
The RMS output voltage is defined as [21]:

$V_{\mathrm{rms}}=\left(\sum_{M=1}^{2 p} \frac{\sigma}{\pi}\right) V_{\mathrm{s}}$

where $V_{\mathrm{s}}$ is the input voltage, $\sigma$ the width of the $m$ th pulse and $p$ the number of pulses per half-cycle.

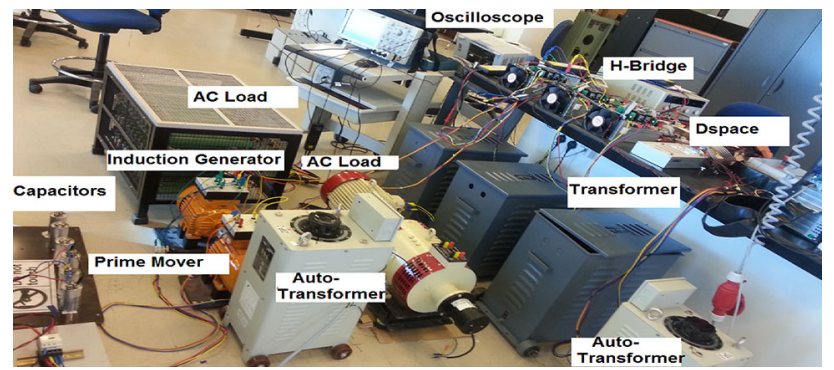

Fig. 7 Hardware used for experimental evaluation

\section{Results and discussion}

The feasibility of the proposed control method has been investigated and verified through computer simulations and experimental results.

\section{Simulation results}

MATLAB/Simulink ${ }^{\circledR}$ modelling is used to examine the effectiveness of the proposed control. The residual magnetism in the machine is taken into account in the simulation process, because it is not possible for the induction generator to be self-excited without it. The three induction generators are rated at $3.6 \mathrm{~kW}$. The relationship between magnetizing inductance $\left(L_{\mathrm{m}}\right)$ and phase voltage for induction machine was obtained experimentally by [22]: $L_{\mathrm{m}}=1.56 \mathrm{e}-11 . v^{4}+2.44 \mathrm{e}-8 . v^{3}-1.19 \mathrm{e}-5 . v^{2}+1.42 \mathrm{e}$ $-3 . v+0.245$.

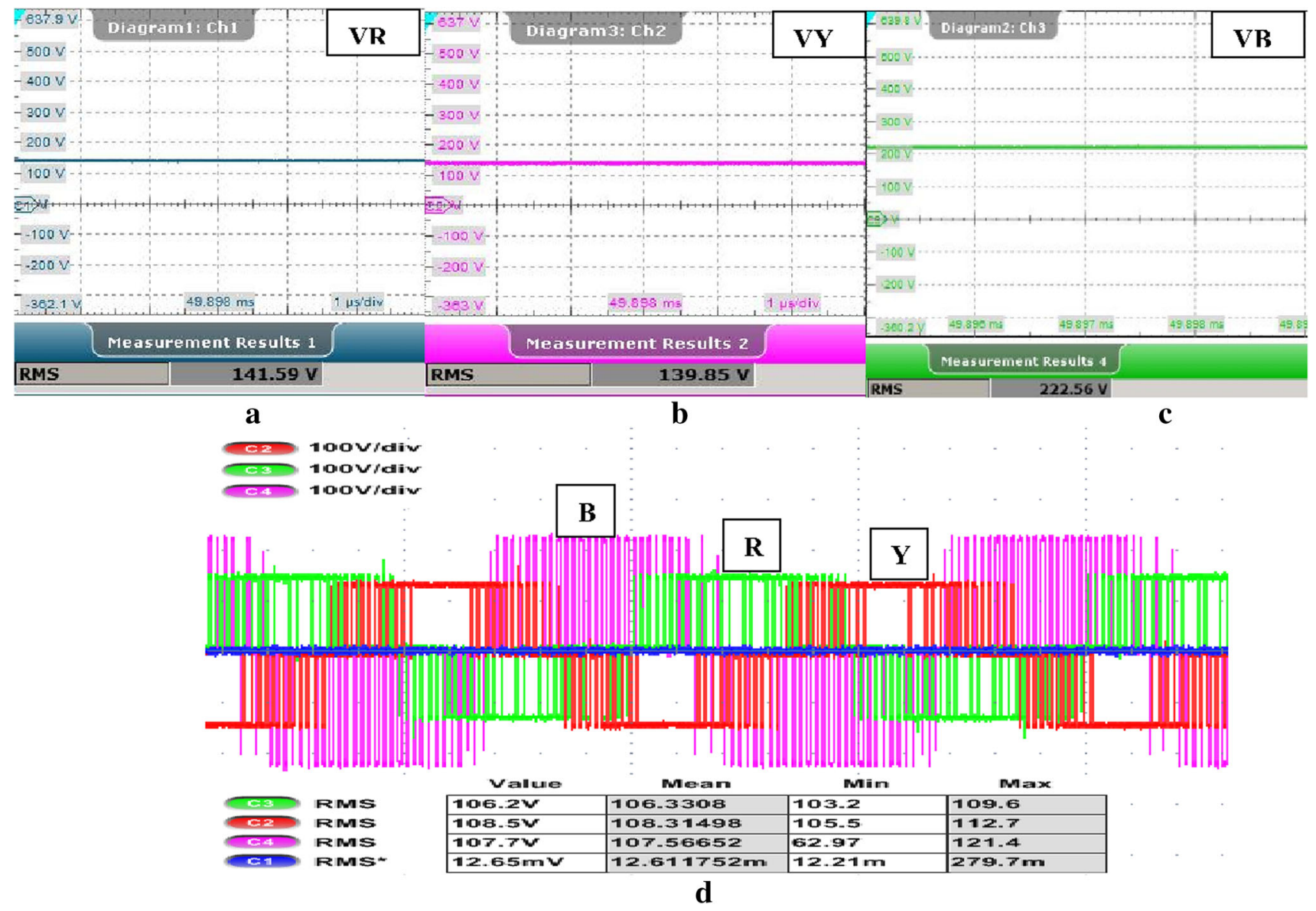

Fig. 8 Performance of the proposed system under different DC input voltages. a DC link voltage of H-bridge 1. b DC link voltage of H-bridge 2. c DC link voltage of H-bridge 3. d AC output voltages of three $\mathrm{H}$-bridges 
The proposed system starts excitation process from capacitors bank of $60 \mu \mathrm{F}$ which are connected across the stator terminals of an induction machine. The global system is tested during $8 \mathrm{~s}$, and the three generators are subjected to step change in the rotor speed as shown in Fig. 3 to give variable DC voltage to the input inverter. The reference RMS voltage of the three H-bridges is set at $230 \mathrm{~V}$ and later changed to $110 \mathrm{~V}$ after $6 \mathrm{~s}$ to show the effectiveness of the controller. The steady state and dynamic behaviour of the system under normal conditions are presented.

Figures 4 and 5 show the effect of the stator terminal voltage and DC link voltage for three generators under variation of rotor speed, respectively.

Constant voltage control is effectively achieved by employing a cascaded three-level H-bridge inverter with controllable output voltage. Simulation results for control voltage are presented for the three induction generators subjected to step changes in the prime mover and reference setting to demonstrate the validity of the proposed control scheme. The simulation results of the proposed system based on three self-excited induction generators under variation of speed obtained from the downscaled prototype confirm the merits as show in Fig. 6.

\section{Experimental results}

The experimental setup of the proposed system as shown in Fig. 7 comprises $1.1 \mathrm{~kW}$ induction generator driven by an induction motor (as prime mover). The generator stator phase output voltages with a capacitor bank for excitation are connected to three-phase diode rectifiers of an H-bridge inverter. Two other H-bridge inverters are connected with a separate isolation transformer. These isolation transformers are fed with an auto transformer to simulate the behaviour of output voltage of SIEG, such as variation of the prime mover. The three output voltages of each cascaded H-bridge inverter are connected to an isolated load. The output phase voltages are fed back through an analogue-todigital converter (ADC) of the DSPACE. The error

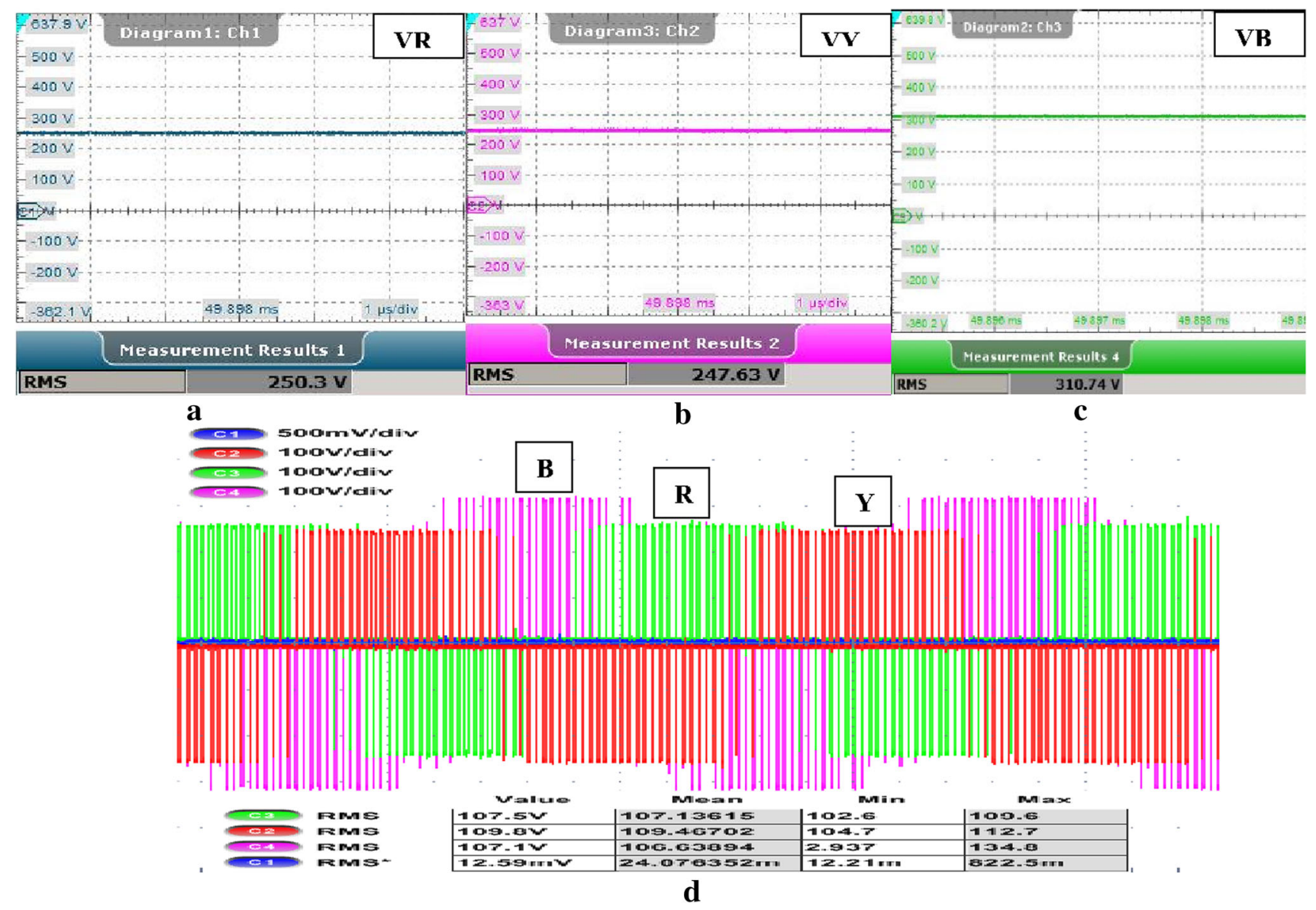

Fig. 9 Performance of the proposed system under different DC input voltages. a DC link voltage of H-bridge 1 . b DC link voltage of H-bridge 2. c DC link voltage of H-bridge 3. d AC output voltages of three H-bridges 


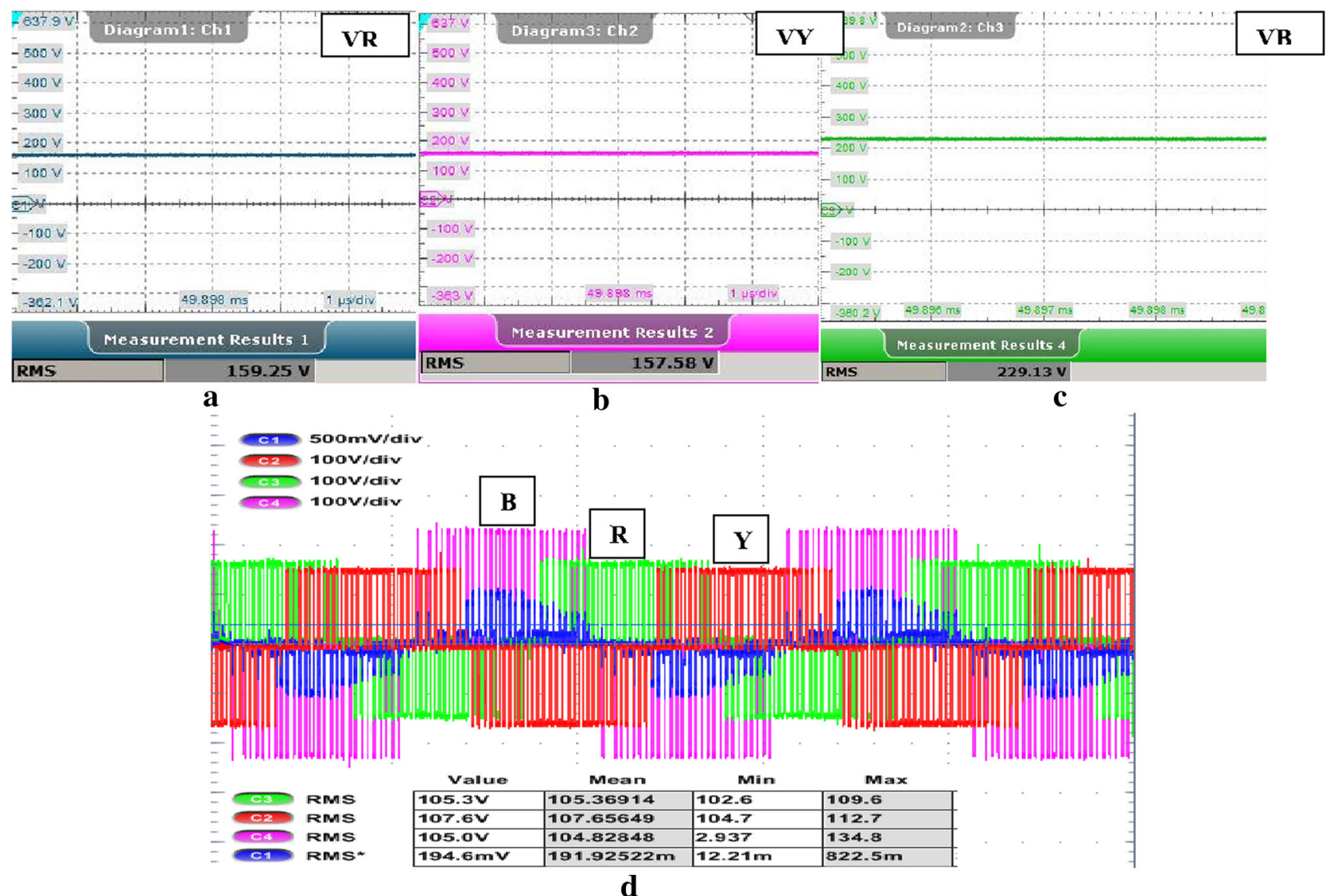

Fig. 10 Performance of the proposed system under different DC input voltages. a DC link voltage of H-bridge 1. b DC link voltage of H-bridge 2. c DC link voltage of H-bridge 3. d AC output voltages of three H-bridges feeding resistive load blue (line current)

between the reference and the feedback signals are passed through PI controllers to generate the modulation indexes used for the PWM signals to switch 12 IGBTs of the cascaded H-bridge inverter.

\section{Performance of the proposed system with step change in $D C$ and load}

The system operates under standalone mode, and the output of the converter is connected with different conditions, no load, a three-phase resistive load and induction motor.

To validate the control scheme in the experiment, the reference voltage is fixed at $110 \mathrm{~V}$ and the experiment is done under variable and unequal DC voltage through changing of the speed of SIEG and the source voltages of the two isolated transformers with an autotransformer.

Measurements are made using the two digital oscilloscopes at the same time with capture screens, in which the first measures the three continuous voltages of the inverter input and the second measures the three simple voltages output of the inverter.
Figures $8 \mathrm{~d}$ and $9 \mathrm{~d}$ show the experimental performance of the control scheme for the output voltage under variable and unequal input DC voltage (Figs. 8a-c, 9a-c) with no load.

Figures $10 \mathrm{~d}$ and $11 \mathrm{~d}$ illustrate the experimental waveforms of the output voltage and line current under unequal DC voltage (Figs. 10a-c, 11a-c) due to variation of source and rotor speed of SIEG feeding resistive load and induction motor, respectively.

Figure $12 \mathrm{~d}$ shows the line to line voltage of three-level cascade H-bridge feeding an induction motor.

The test experiments are conducted to demonstrate the response of the close loop system; the modulation index is changed to achieve the desired RMS phase voltage with balanced operation of a three phase. The system behaves with variation in DC link voltage, while the RMS AC output voltage is maintained constant as evident from Table 2. It is worth mentioning that the inverter usually operates with effectiveness for all the five cases as shown from Figs. 8, 9, 10, 11 and 12. 

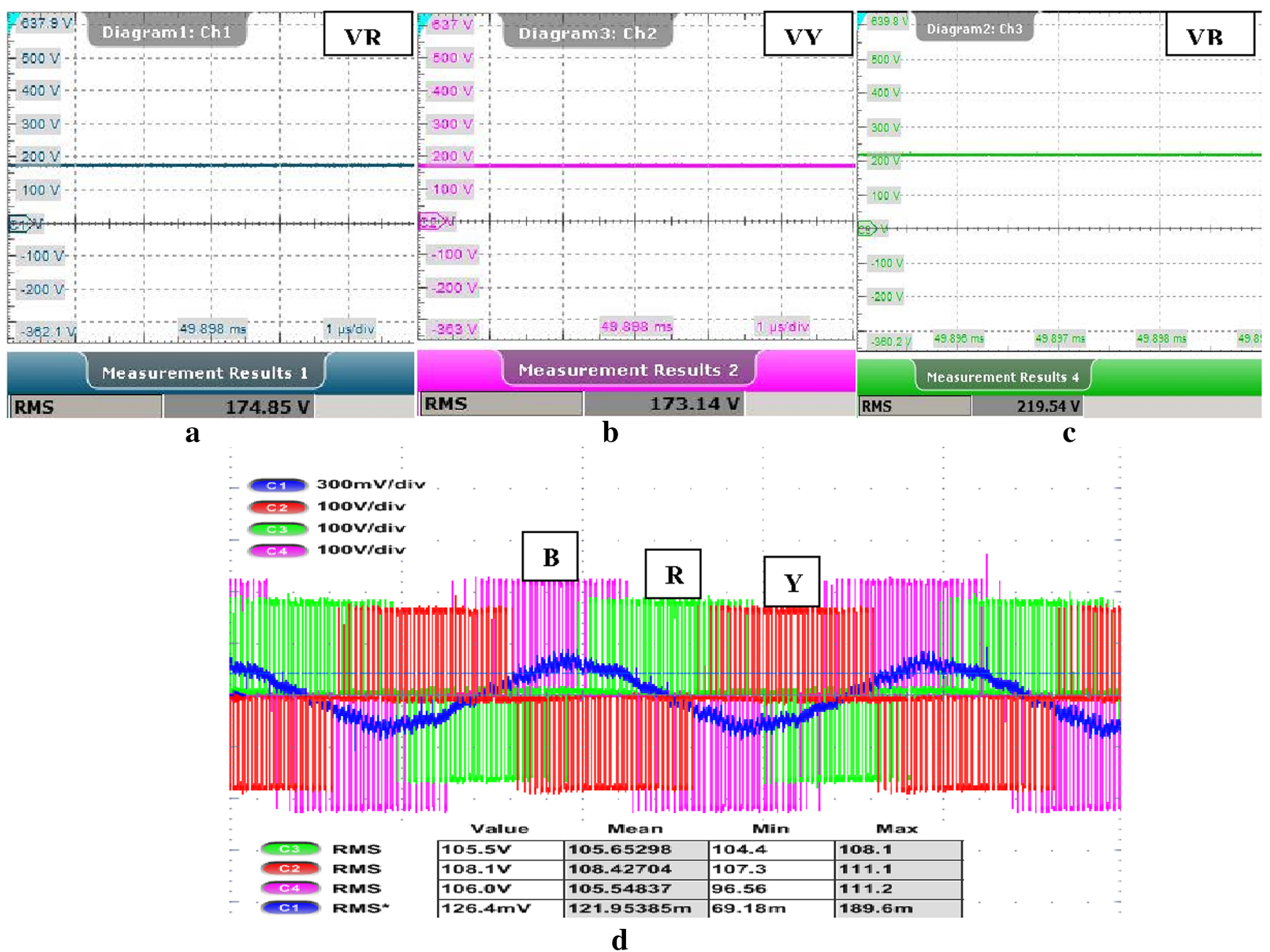

Fig. 11 Performance of the proposed system under different DC input voltages. a DC link voltage of H-bridge 1. b DC link voltage of H-bridge 2. c DC link voltage of H-bridge 3. d AC output voltages of three H-bridge feeding induction motor blue (line current)

The performance of renewable energy system based on small power generation working independently and parallel through voltage regulation is investigated in experimental results for no load, resistive load and inductive load. It is shown that the output AC load voltage can be effectively kept at a fixed value of around $110 \mathrm{~V}$ for balanced operation of a three-phase isolated load regardless of perturbation of source and application of loads.

In both the simulation and experimental tests, the RMS voltage effectively tracks to their references even with the variation and inequality of the DC link. A robust performance is obtained. The proposed method can be easily extended to other renewable source such as the PV system to achieve optimal performance with good quality.

\section{Conclusion}

This study proposes an effective control voltage configuration for three SIEG-based renewable energy supplies (micro-hydraulic or wind). A comprehensive simulation study demonstrates the performance of the proposed system during variable speed conditions of the three generators. It has been observed that the controller is capable of regulating the output voltage.

The specific contribution of this paper is summarized as follows:

- Suitable topology for application of small power generation using induction generator in isolated location by three-level cascade $\mathrm{H}$-Bridge. 


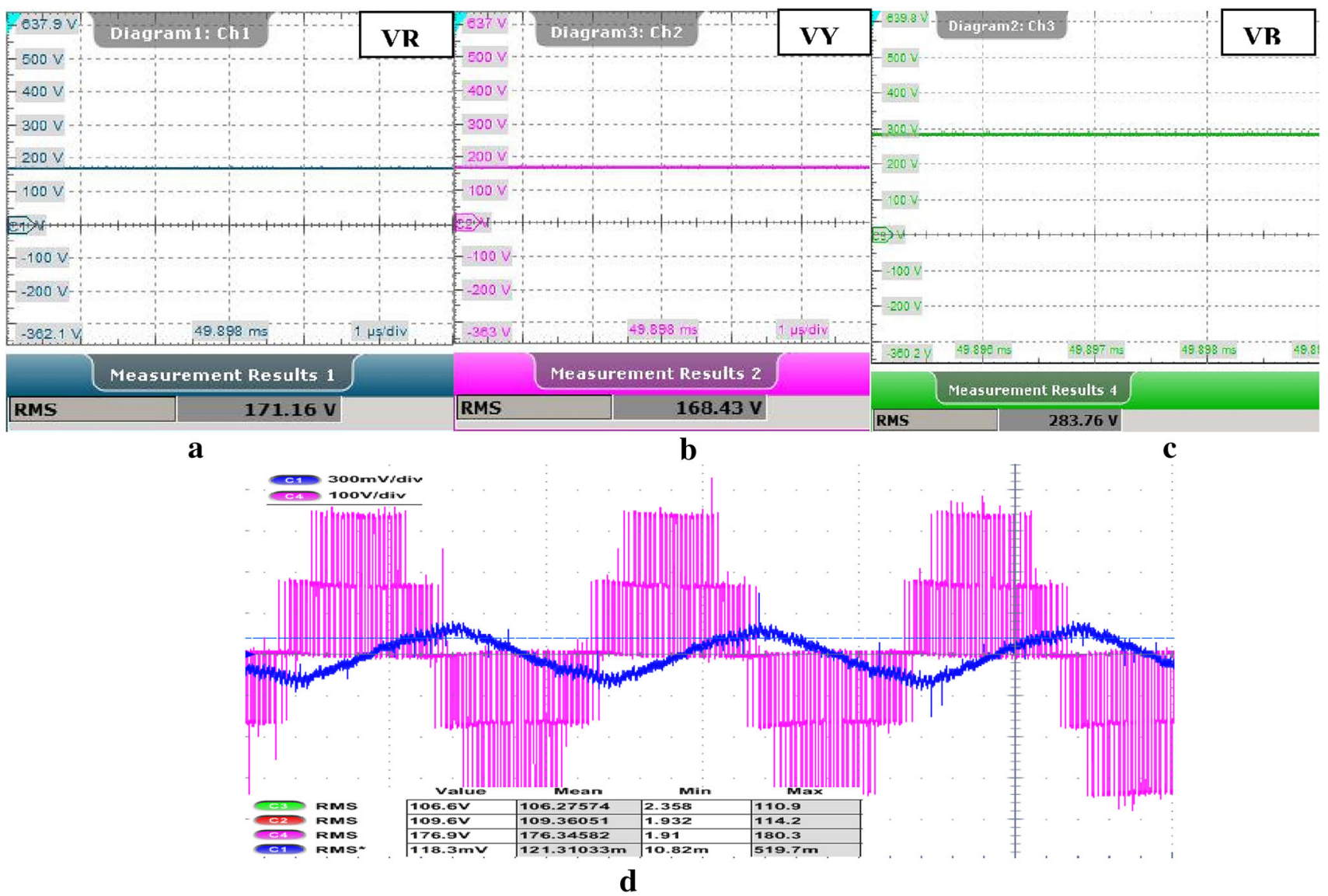

Fig. 12 Performance of the proposed system under different DC input voltages. a DC link voltage of H-bridge 1. b DC link voltage of H-bridge 2. c DC link voltage of H-bridge 3. d AC line to line output voltage of $\mathrm{H}$-bridge and current feeding induction motor

Table 2 Results

\begin{tabular}{lllllll}
\hline Figure & $V_{1}$ & $V_{2}$ & $V_{3}$ & $V_{\text {a_rms }}$ & $V_{\text {b_rms }}$ & $V_{\text {c_rms }}$ \\
\hline $\begin{array}{lllllll}\text { No load } \\
8\end{array}$ & & & & & & \\
9 & 141.44 & 139.17 & 139.12 & 106.7 & 108.6 & 106.6 \\
10 & 250.3 & 247.63 & 310.74 & 107.6 & 109.8 & 107.1 \\
\multicolumn{1}{l}{ With load } & & & & & \\
11 & 159.25 & 157.58 & 229.13 & 105.3 & 107.6 & 105 \\
12 & 174.85 & 173.14 & 219.54 & 105.5 & 108.1 & 106 \\
\hline
\end{tabular}

- Proposed control scheme for the output voltage regulation of three cascades H-bridge inverter without DC bus voltage regulation with $\mathrm{DC} / \mathrm{DC}$ converter in the input of the H-bridge.

- The system is designed in a flexible and versatile way for the investigation of different hybrid schemes of renewable energy generation

Acknowledgments The authors gratefully thank the Power Electronics Research Lab, the Petroleum Institute, for the facilities and support for this research. We specially thank Mr. Saikrishna Kanukollu for his valuable assistance in this work.

Open Access This article is distributed under the terms of the Creative Commons Attribution 4.0 International License (http://crea tivecommons.org/licenses/by/4.0/), which permits unrestricted use, distribution, and reproduction in any medium, provided you give appropriate credit to the original author(s) and the source, provide a link to the Creative Commons license, and indicate if changes were made.

\section{References}

1. Leva, S., Zaninelli, D.: Hybrid renewable energy-fuel cell system: design and performance evaluation. Electr. Power Syst. Res. 79, 316-324 (2009)

2. Iannone, F., Leva, S., Zaninelli, D.: Hybrid photovoltaic and hybrid photovoltaic-fuel cell system: economic and environmental analysis. In: Power Engineering Society General Meeting, 2005. IEEE, vol. 2, pp. 1503-1509, 12-16 June 2005

3. Leva, S.: Dynamic stability of isolated system in the presence of PQ disturbances. IEEE Trans. Power Deliv. 23(2), 831-840 (2008)

4. Rekioua, D.: Wind Power Electric Systems, Green Energy and Technology. Springer, London (2014) 
5. Chan, T.F.: Capacitance requirements of self-excited induction generators. IEEE Trans. Energy Convers. 8(2), 304-311 (1993)

6. Al-Jabri, A., Alolah, A.I.: Limits on the performance of the threephase self-excited induction generators. IEEE Trans. Energy Convers. 5, 350-357 (1990)

7. Malik, N.H., Mazi, A.A.: Capacitance requirement for isolated self-excited generators. IEEE Trans. Energy Convers. 2, 62-69 (1987)

8. Chakraborty, C., Bhadra, S.N., Chattopadhyay, A.K.: Excitation requirements for standalone three-phase self-excited induction generator. IEEE Trans. Energy Convers. 13(4), 358-365 (1998)

9. Chan, T.F.: Steady-state analysis of selfexcited induction generators. IEEE Trans. Energy Conversion 9(2), 288-296 (1994)

10. Goel, P.K., Singh, B., Murthy, S.S., Kishore, N.: Isolated windhydro hybrid system using cage generators and battery storage. IEEE Trans. Ind. Electron. 58(4), 1141-1153 (2011)

11. Wang, L., Chen, H.W., Lee, D.-J.: Implementation of a DSPbased power converter for a wind induction generator. In: Power and Energy Society General Meeting-Conversion and Delivery of Electrical Energy in the 21st Century, 2008 IEEE, pp. 1-6, 20-24 July 2008

12. Chilipi, R.R., Singh, B., Murthy, S.S.: Performance of a selfexcited induction generator with DSTATCOM-DTC drive-based voltage and frequency controller. IEEE Trans. Energy Convers. 29(3), 545-557 (2014)

13. Wang, L., Lee, D.-J.: Coordination control of an AC-to-DC converter and a switched excitation capacitor bank for an autonomous self-excited induction generator in renewable-energy systems. IEEE Trans. Ind. Electron 50(4), 2828-2836 (2014)

14. Singh, B., Kasal, G.K., Chandra, A., Al Haddad, K.: Voltage and frequency controller for an autonomous micro hydro generating system. In: Power and Energy Society General Meeting-Conversion and Delivery of Electrical Energy in the 21st Century, 2008 IEEE, pp. 1-9, 20-24
15. Chen, W.-L., Hsu, Y.-Y.: Experimental evaluation of an isolated induction generator with voltage and frequency control. In: Power Electronics, International Symposium on Electrical Drives, Automation and Motion, SPEEDAM 2006., May 2006, pp. 497-502, 23-26

16. Chauhan, P.J., Chatterjee, J.K.: Single-loop voltage and frequency control schemes for SEIG-battery storage based standalone three-phase four-wire RECS. In: International Conference on Power and Energy Systems (ICPS), pp. 1-6, 22-24 Dec. 2011

17. Kouro, S., Malinowski, M., Gopakumar, K., Pou, J., Franquelo, L.G., Wu, B., Rodriguez, J., Pérez, M.A., Leon, J.I.: Recent advances and industrial applications of multilevel converters. IEEE Trans. Ind. Ele. 57(8), 2553-2580 (2010)

18. Taha, O.A., Pacas, M.: Hardware implementation of balance control for three-phase grid connection 5-level Cascaded H-bridge converter using DSP. In: IEEE 23rd International Symposium on Industrial Electronics (ISIE), pp. 1366-1371, 1-4 June 2014

19. Colak, I., Kabalci, E., Bayindir, R., Bal, G.: Modeling of a three phase SPWM multilevel VSI with low THD using Matlab/ Simulink. In: 13th European conference on Power Electronics and Applications, 2009. EPE '09, Sept. 2009, pp. 1-10, 8-10

20. Seyoum, D., Grantham, C., Rahman, F.: Analysis of an isolated self-excited induction generator driven by variable speed prime mover. In: Proc. AUPEC'01, 2001, pp. 49-54

21. Tiang, T.L., Ishak, D.: Modeling and simulation of deadbeatbased PI controller in a single-phase $\mathrm{H}$-bridge inverter for standalone applications. Turk J Elec Eng Comp Sci 22, 43-56 (2014)

22. Seyoum, D., Grantham, C., Rahman, M.F.: The dynamic characteristics of an isolated self-excited induction generator driven by a wind turbine. IEEE Trans. Indus. Appl. 39(4), 936-944 (2003) 